\title{
Global Perspectives on Smart-Power Strategy in International Arena: Critical Discovery into Philosophy of Clausewitz and Sun Tzu from Strategic Implications
}

\author{
Barack Lujia Bao 8 (D) \\ Faculty Fellow and Researcher, Xianda College of Economics and Humanities of Shanghai International Studies University, \\ Shanghai, China \\ $\triangle$ Corresponding Author: Barack Lujia Bao, E-mail: baolujiamzd@qq.com; 2011068@xdsisu.edu.cn
}

\author{
ARTICLE INFORMATION \\ Received: August 06, 2021 \\ Accepted: September 05, 2021 \\ Volume: 3 \\ Issue: 9 \\ DOI: 10.32996/jhsss.2021.3.9.2
}

\section{KEYWORDS}

International Studies; Smart-Power Strategy; Sun Tzu; Clausewitz; International Development; CrossCultural Studies

\section{ABSTRACT}

Within the military discipline, the doctrine from Carl von Clausewitz and Sun Tzu can be framed as the ones among the most influential strategy-based philosophical domains. Carl von Clausewitz's theoretical framework of consolidation of all powers and strategic obliteration of all forces of the opponents and rivals seems not uncommon in analysing the scenarios of international power competition and contest. On the contrary, Sun Tzu (around 545B.C.-470B.C.), the ancestral Chinese military strategist during the Spring and Autumn Period, put forward the complete distinctive strategic conception of optimum winning without engaging in any fight, which meanwhile plays a more epistemologically productive, thought-provoking role in utilising smart power strategy in a complex, evolving international arena where hard power alone has been of no avail to keep a dominantly advantageous position. Sequentially, it is indispensable for strategists to conduct in-depth exploration into the role of smart power through abstractly inheriting the consequential philosophical implications from Sun Tzu and Clausewitz as a distinctive strategy-building element and eclectically and rationally combine, enliven and hierarchise their implicit ties with an authentic world matrix that it is hard to empirically theorise and accurately quantify. Through deductive-analysis approaches and case studies of the US (a dominant power in relative terms over the long run), China (the second-largest economic power thus far) and India (a rising power in BRICS), the primary purpose of this paper seeks to dialectically explore an implicit dyadic nexus between 1) the philosophical implications for Sun Tzu and those for Clausewitz and 2) the nature and implementation of smart power strategy ranging from the perspectives of historical origin and international context. It can be argued that the philosophical standpoint of smart power strategy bears historical merits that the principal arguments from Clausewitz and Sun Tzu somehow generated. This paper-based on existential research findings meanwhile prognosticates that the strategic implementation of smart-power strategy, which tends to be highlighted worldwide in the foreseeable future, will advance in a world of multipolarisation instead of bipolarity and strategic co-opetition (i.e. cooperation and competition combined) will grow as an alternative widespread international phenomenon and trajectory that complicates the magnetism, flexibility and unpredictability of how a broad definition of national strength would influence the international structure and international standing.

\section{Introduction}

In today's world of multipolarity, it can be seriously observed that against the backdrop of an unprecedentedly complex international arena of constant changes and inter-civilisational exchanges, no longer will hard power alone keep a state actor or a civilisational entity at a perpetual advantageous position in an international context, nor can even soft power alone do so; no

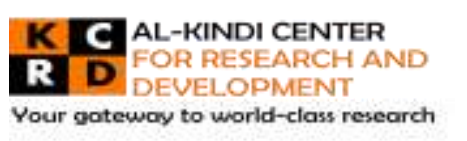

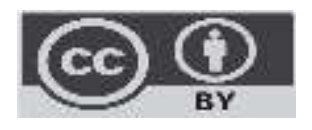

Published by Al-Kindi Center for Research and Development. Copyright (c) the author(s). This open access article is distributed under a Creative Commons Attribution (CC-BY) 4.0 license 
longer will smart power strategy be a pending philosophical concept merely recorded on documents without careful assessment and calibration. Since the end of bipolar-system period, the US has become the military and economic superpower over a long period, not merely because of the scope and size of its military power, but more importantly because of its strategy of spreading US soft-power elements that significantly influence the rest of the globe. Within a certain period, the US becomes a natural beneficiary of such popularity of soft power. However, owning to ill-advised dismissal to smart power strategy in dealing with the international environment, the United States has been suffering from international credibility deficiency and moral authority dilemma that tends to cause the vacuum of condition for the use of smart power. On the contrary, as China continues to rise at an inter-regional level, thanks to the strategy of external development and engagement on the world stage, the dynamism of uninterrupted, sustainable Chinese civilisation provides the condition for implementation of smart power in international engagement, which helps to generates China to heighten its international credibility index. Beyond those two largest economic powers from the Western Hemisphere and Oriental Hemisphere, as a rising member in BRICS, India has been on the track of adoption of smart power strategy on the basis of India's chronic civilisations and attractions of India's technology and human capital in a world of multipolarisation.

In accordance with the above-mentioned examples, it has been carefully observed that smart-power strategy has been on the track of being nearly put on the agenda and of generally acknowledged as a new important, different kind of strategy of international inter-civilisational development and international engagement. It is critical for analysts and strategists to detect the origin and nature of smart power strategy from ancient civilisations. It can be argued that within the military discipline, the dogmas from Sun Tzu (around 545B.C.-470B.C.) and Carl von Clausewitz (1780-1831) can be framed as the ones among the most influential strategy-based philosophical domains over the course of human civilisations. For instance, Clausewitz's theoretical framework of consolidation of all powers and strategic obliteration of all forces of the opponents and rivals seems not uncommon in evaluating the scenarios of power competition and contest at an international level. On the contrary, Sun Tzu, an ancestral Chinese military strategist during the Spring and Autumn Period, put forward the distinctive strategic philosophy of winning without engaging in any fight, which plays a more epistemologically productive, thought-provoking role in utilising smart power strategy in a complex, evolving international arena where harsh, coercive hard power alone has been of no avail to keep a dominantly advantageous position. The primary purpose of this paper seeks to serve as a theoretic bridge of strategystudy philosophical conceptions from Sun Tzu and Clausewitz and Smart Power Strategy, which may be fairly more explanatory and pragmatic in transnational cooperation, competition and even co-opetition, i.e. a cyclic flow of cooperation and competition in the international-relations theoretical context beyond bipolar system.

Here are certain hypothetical research questions to which this paper attaches much importance. What is the nature of smart power strategy? Is there any kind of embryonic form of smart power strategy from Sun Tzu and Clausewitz? Upon what benchmark should smart power strategy by different state actors be empirically evaluated? The paper attempts to dialectically emphasise the implicit and dynamic interplay between fundamental conceptions from a strategically and methodologically influential The Art of War by Sun Tzu and from On War by Clausewitz, and conceptions of diverse experts in international relations from diversification of theoretical perspectives. This paper values theoretical and empirical inquiry between On War and The Art of War as well as adoption and implementation of smart power strategy in a complex contour of international issues, such as clash or competition of civilisations, global governance mechanism, technological advancement, climate and public health crisis and so forth. Some of these strategic conceptions from Clausewitz and Sun Tzu and smart-power strategy are epistemologically and methodologically non-contradictory and to a large degree complementary to one another (for example, strategic dominance and deterrence against the opponents vs winning without any fight, etc.), whereas other strategic methodologies are usually seen as competitive or even mutually incompatible to one another (for example, strategic winning with obliterating the armed force of the opponents for the sake of superiority vs. winning without any fight, etc.). Regardless, today's transnational development and inter-civilisational exchanges further embrace a wide range of substantive strategic themes, some of which have an elective affinity with particular theoretical approaches that the strategies proposed by Clausewitz and Sun Tzu and smart power strategy share, from which this paper seeks to theoretically combine, enliven and hierarchise some could-be eclectic philosophical spotlights because whether they are valid theory is distinguished by how well their internal logic, implications and dynamics can help lead the intellectuals and strategists to fresh empirical insights into the world as it is and normative insights into the world as it should be.

The composition of this paper is divided as follows. To begin with, the paper seeks to identify a diversification of interpretations of power in academia, which can lay a discernible, theoretic foundation for systematically conducting deductive analysis of how the concept of powers has been utilised in international arena of multipolarisation and of how it may have potential links to the philosophical doctrines of Clausewitz and Sun Tzu. The second part of this paper attempts to dialectically and eclectically discover the philosophical merits of strategy from Clausewitz and Sun Tzu in a comparative fashion that plays a role of linchpin between occidental strategic-study achievements and the counterparts of oriental strategic studies. Third, their meritorious reciprocity outweighs their considerable disparity owning to different historical contexts and civilisations, which generates an 
embryonic theoretic prototype of smart power strategy. The following case study of the US (a dominant power in relative terms over the long run), China (the second-largest economic power thus far) and India (a rising power in BRICS) can be the hermeneutic reinforcement of the necessity of properly designing and implementing smart power strategy out of bipolarity mentality. Ultimately, this paper has profound inclinations to make a significant difference in philosophically internalising shouldbe well-designed smart power strategy in a world of high unpredictability and no uniform benchmark in the $21^{\text {st }}$ century of multipolarity.

\section{Deductive Analysis of Tenets of Power Strategy in Alignment with Clausewitz and Sun Tzu 2.1 Dyadic Nexus between Hard Power and Soft Power}

The concept of power has become an inevitable theme within the international-relations discourse with heterogeneous articulations and interpretations in academia and strategy-studies communities. A generally-acknowledged methodology of assessing power lies in quantifying, hierarchising and evaluating the nature and scope of it and resources of power. At Kennedy School of Government of Harvard University, Professor Joseph Nye frames power as the important capability to affect others to acquire certain objectives, whose means entail a set of targeted instruments, of coercion, and of attraction (Nye, 2008). Moreover, it is worth noting that the resources of power embrace 1) hard power, which may be more empirically tangible and measurable, whose role tends to force others' behaviours and achieve objectives through certain rewards or sticks, and 2) soft power, which is abstractly intangible and indiscernible without certain paradigms and leverages, whose comparable role attempts to have the people around do what they volunteer to do through attractions rather than coercive means (Zhang, 2004; Keohane \& Nye, 1998). Within a micro-level context, Professor Nye argues that for individual's charisma, vision, and effective strategic communication are consequential soft-power tactics (Nye, 2008). For instance, within a framework of a corporate organisation, how well soft power strategy as a benchmark on transformational leadership is adopted may determine how strategically the managers can motivate people to deliver the objectives they demand (Nye, 2008). When it comes to a macrolevel analysis, soft power is embodied in culture, values, and policies that embrace legitimacy (Nye, 2008). The state actors or international actors that are likely to acquire soft power are those having an affinity for "global norms of liberalism, pluralism, and autonomy; and those whose credibility is enhanced by their domestic and international performance" (Li, 2017: 255). Li Qin's arguments and observations are comparable to democratic-peace theory whilst the arguments is subjected to classical Westerninitiating international relations discourse that tends not to well explain what happens in the Oriental Hemisphere or even every state actor and partly fall short of analysis of nexus between the potential deterministic role of national interest and operation of international engagement.

Here is a corresponding question: what is the real essence of soft power? Plenty of intellectuals and strategists tend to launch diverse explanations correspondingly; however, few explanations can be the perfectly accurate quantification of this nomenclature except those propositions made by Joseph Nye, Robert Keohane and even Hans. J. Morgenthau can be viewed as the comparable reference for defining the substance, condition, and scope of soft power. Professor Joseph Nye compartmentalises resources of soft power mainly with three chief independent variables, i.e. culture, ideology and international system (Nye, 2005). Put it further, the resources that produce soft power for a state actor encompass its culture of how attractive it is to others, its values unencumbered by inconsistent practices in a fast-changing international environment and its policies of inclusivity and legitimacy (Zhang, 2011). It can be deduced that soft power derives from intangible power resources like culture, ideology and influence on international institutions (Keohane \& Nye, 1998). When "soft power" is used, that nation would try to have others to internalise its systematic rules on a voluntary basis through popularity and magnetism of ideas or determinations of political issues (Zhang, 2004). Of course, more essential doctrines can be abstractly extracted from the resources of soft power. Making no mistake, the role of culture in influencing international affairs and structure is indiscernible but existential and the definition of culture encompasses no singular uniformity because the complexity of defining it rests from anything but what to include; instead, it does from what to exclude (Hudson, 1997; Kaura, 2021).

If a time can be dated back to the USSR-US-based bipolar period, this nomenclature of soft power may include another embryonic prototype. The hermeneutic interpretation made by Hans. J. Morgenthau, a renowned international-relations expert from Politics Among Nations (1956) can be identified as a supplementary exemplification of the two-power nexus (Li, 2006). Hans. J. Morgenthau highlighted that in the international arena, not merely is contention for power a contention for superiority and rule, but to a large degree, it is contention for public ideology (Morgenthau, 1956). Moreover, a nation's power is dependent upon not singularly its diplomatic prowess and military strength, but significantly the appeal of its philosophy of administration and governance, institutions and policies to other state actors (Morgenthau, 1956). Morgenthau's conceptions of soft power engender conceptional evolution made by Joseph Nye and Robert Keohane. It is worth noting that In a world of increasing interdependence, the use of power grows less coercive and less tangible, soft co-optive power carrying greater weight than hard power on the world stage $(\mathrm{Li}, 2017)$. The following consequential reasons can explain and exemplify the above-mentioned phenomenon. To begin with, albeit in some ways, military force remains crucially influential in strategic deterrence and national defence, economic, environmental, and technological issues and the like cannot be thoroughly resolved through the means of 
hard power. Next, in the contemporary world, hard power is more problematic to deploy due to rising global issues, power diffusion and nearly deterministic role of geo-economic diffusion, and powerful synergy and competition are far more complex and unpredictable than they were in bipolar systems. Oftentimes, rivals may maintain certain cooperative areas for the sake of national interest, whereas alliances and partners may go through transnational disagreements that are highly likely to negate their partnership. Furthermore, if a state actor's power is appealing, legitimate, and justifiable, it may achieve goals at a nominal expense.

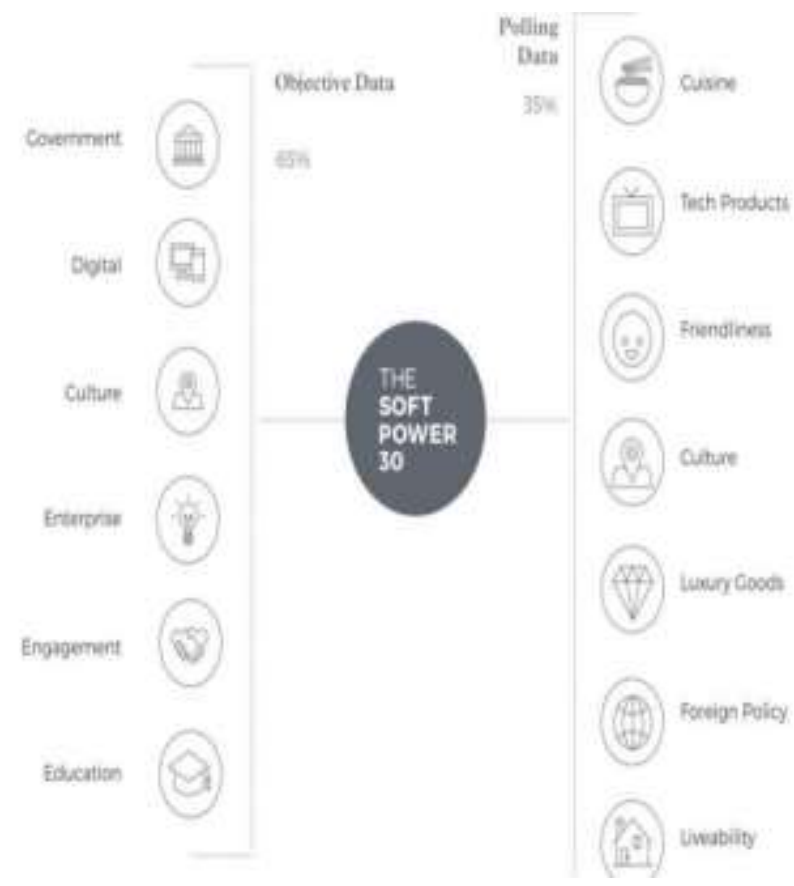

Note: From "The Soft Power 30 Framework" by USC Centre on Public Diplomacy, 2019, The Soft Power: a Global Ranking, 2019, The Soft Power 30: A Global Ranking of Soft Power 2019. p.11. Copyright by USC Centre on Public Diplomacy. Permission not sought.

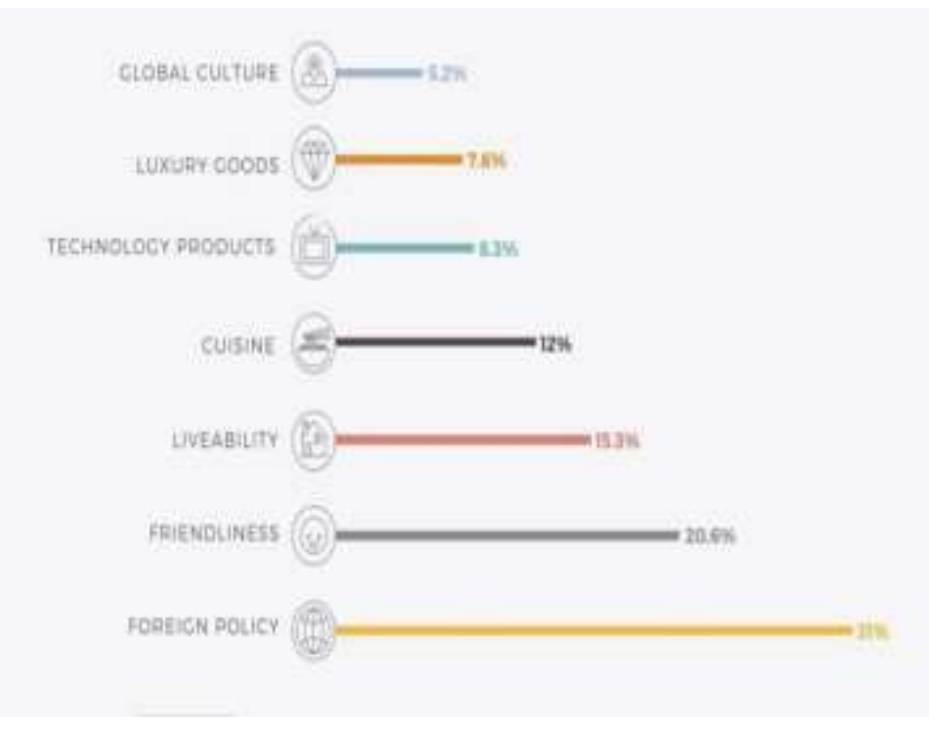

Note: From "Weighting of the Polling Categories" by USC Centre on Public Diplomacy, 2019, The Soft Power: a Global Ranking, 2019, The Soft Power 30: A Global Ranking of Soft Power 2019. p.32. Copyright by USC Centre on Public Diplomacy. Permission not sought. 


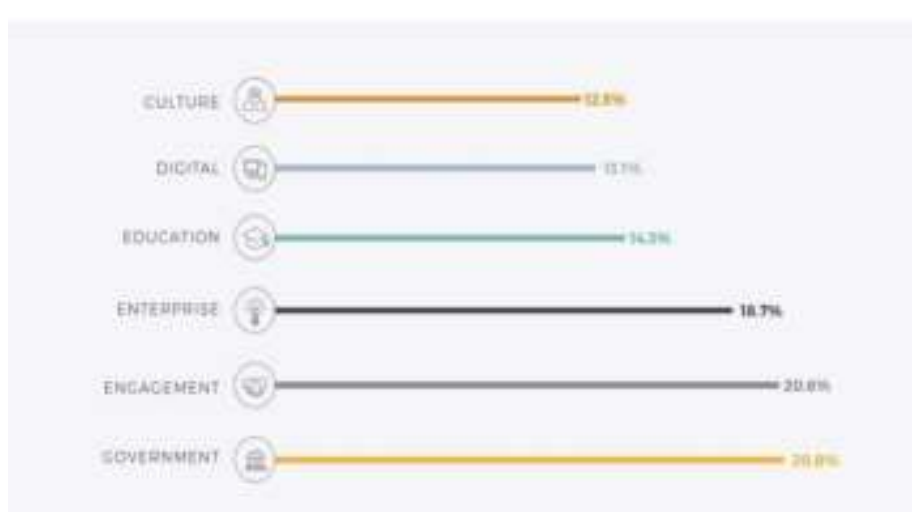

Note: From "Weighting of the Objective Sub-indices" by USC Centre on Public Diplomacy, 2019, The Soft Power: a Global Ranking, 2019, The Soft Power 30: A Global Ranking of Soft Power 2019. p.33. Copyright by USC Centre on Public Diplomacy. Permission not sought.

To be sure, hard power is the fundamental prerequisite to the reinforcement of soft power. In contrast, the reinforcement of soft power likewise helps to aggrandise hard power, which is theoretically equivalent to the concept by Joseph Nye that it is illusory for soft power alone can resolve complex international issues (2009). Meanwhile, there is no negative correlation between hard power and soft power: provided that hard power is weakening, then the probability of the downward trajectory of soft power will be high, and when the growth of soft power lags behind, the restrictive, limited expansion of hard power will probably occur (Li, 2006).

\subsection{Smart Power Strategy from Sun Tzu and Clausewitz from the Contemporary Perspectives}

All above-mentioned theory normally has profound links to the research findings of intellectuals and strategists of the modern and contemporary times. However, the questions of whether ancestral experts at much earlier times and their strategic-study legacies bear certain hints and implications for strategy-power nexus should be investigated in a comparable fashion. The author of this paper finds that two distinctive strategists from the Occidental Hemisphere (i.e. Carl von Clausewitz) and Oriental Hemisphere (i.e. Sun Tzu) can be the alternative reference. By paraphrasing Dr.Henry Kissinger's statements, whereas Clausewitzgenerating methodology normally treats history as a process of modernity achieving a series of absolute victories over evil and backwardness, Sun Tzu's methodology of history emphasised a cyclical process of decay and rectification, in which nature and the world can be grasped holistically but not accurately deconstructed and interpreted (Kissinger, 2011). Moreover, methodologically speaking, whereas Clausewitz's strategy reflects more on assembling superior power at the decisive point, Sun Tzu's strategy addresses the means of achieving "a dominant political and psychological position" (Kissinger, 2011: 30).

The question of what can be abstracted learned from the strategic conceptions proposed by Sun Tzu requires in-depth research. Over the course of the Spring and Autumn Period and Warring State Period, one characteristic of Sun Tzu's smart power strategy is his philosophical development and pivot of psychological thought and flexibility in avoidance of direct attack and confrontation under the circumstance that the force remains underdeveloped at a disadvantageous position. It is linked to Sun Tzu's highlight that war is a major event for the rise and fall of a state, which requires maximum careful deliberation. Over two thousand years after its composition, this volume of epigrammatic observations on strategy, diplomacy, and warfare from The Art of War remains a central document of military thought, especially Sun Tzu's strategic proposition of indirect attack and psychological combat against opponents and adversaries. Dr. Henry Kissinger, the former US National Security Advisor, is pessimistically acquiescent that "the disregard of his percepts was importantly responsible for America's frustration in its Asian wars" (Kissinger, 2011: 29). Another distinctive characteristic of smart power strategy from The Art of War lies in anything but winning every battle but rather in defeating the opponents and adversaries without ever fight, whose highest form of warfare is to efficiently dismantle the enemy's strategy itself, followed by the defeat of the latter one's alliances and armed forces if the state is at stake. In accordance with The Art of War, victory is not simply the triumph of armed forces. Instead, it is the achievement of the ultimate political objectives that military clash was intended to secure (Sun, 2002). Far more preferable than defeating the opponents on the battlefield is undermining an enemy's rationale or maneuvering him into an absolutely unfavourable position from which escape is largely implausible (Kissinger, 2011).

Like the studies of Sun Tzu's strategy, what can strategists abstractly extract from the detailed exegesis of Clausewitz for the study of strategy? In the first place, Clausewitz's critical exploration covers 1) how quantities and qualities influence each other in war and 2) in what way the fog of war puts a veil of unpredictability over information and falsifiable disinformation. Second, Clausewitz investigates how the strategy could be studied in different contexts. On the one hand - on the basis of his famous proposition that war is the continuation of politics through alternative means - Clausewitz's suggestion lies in framing strategy 
as a socio-political mechanism through which the population and individuals can be convinced in deliberations about a specific course of action (Clausewitz, 1874). On the other hand, Clausewitz deeply emphasised the pedagogical guidance regarding strategy. Rarely does On War offer a normative doctrine but rather a critical theory that equips the strategists to master the task without being perplexed by the potential secret of victory (Kornberger, 2013). Researching Clausewitz's strategy is symbolic of tracing back to a point in the history of ideas where strategy formed out of the concern for the possibility of rational conduct of action in an environment where action, anticipated reaction and ongoing calculation of their play make a prediction of interventions and condition problematic (Kornberger, 2013).

2.3 Reciprocity of Intrinsic Theoretic Merits from Clausewitz and Sun Tzu within Smart-Power Discourse As has been critically discussed, the positive correlation between soft power and hard power, whose organic combination is encapsulated into smart power, helps these two powers to interwove and influence systematically in a comparable way of checks and balances ( $\mathrm{Li}, 2006)$. Albeit in most ways smart power is a conception of abstraction in relative terms and hard to be accurately quantified in an empirical way, it remains necessary for analysts and intellectuals to seek an original theoretical framework to make an accurate assessment of smart power strategy, including some indexes and empirical data as benchmarks.

It can be argued that the disparity of historical background and strategic methodologies from Clausewitz (a strategist from the Napoleonic Era) and Sun Tzu (a strategist from the Spring and Autumn Period) will not affect their potential reciprocity. In the first place, smart power strategy from The Art of War advocates the importance of extensive analysis and logistical, diplomatic, and psychological preparation and relevant resources available partly because strategic deterrence is based on the logic of consequence on an opponent's strategy and partly because in a strategic contest, nothing is statically in isolation but most factors, tangible and intangible alike, are interwoven: e.g. meteorological phenomenon, terrain, diplomatic circumstances, the reports of agents, supplies and logistics, the balance of forces, historical perceptions, and so forth (Kissinger, 2011). Likewise, Clausewitz proposes that generalship is acquired merely by experience and the study of the campaigns of all great captains because in war, everything is uncertain and viable, intertwined with psychological forces and effects, and the product of a continuous interaction (Clausewitz, 1874). Moreover, Clausewitz's smart power strategy proposes the sine qua non of limited war strategy that should be compatible with a specific political objective (Clausewitz, 1874). Likewise, Sun Tzu's strategy is inextricably linked with his definition of the importance of waging war cautiously because war makes a definitive difference in a state's trajectory and strength.

Suppose an organic combination between Clausewitz and Sun Tzu at a philosophical level is in line with the conception of smart power. In that case, it could be argued that smart power strategy meanwhile reinforces the scale of military power and economic strength and comprehensive calculations and leadership strategy. For instance, smart pre-emptive action in justification of national interest should be in line with effective, diplomatic methodologies such as strategic deterrence to the proliferation of weapons of mass destruction and coordinated, sustainable economic development, which "have the potential to eliminate threats from opponents long before military action" (Nossel, 2004: 138). That is a kind of theoretic ramification of Clausewitz's highlight on absolute superiority of power and Sun Tzu's highlight on the nexus between national strength and careful warwaging decision. Furthermore, suppose one organisation or a state of an actor is at a disadvantageous position or at least on the defensive. In that case, smart power strategy may entail strategic communication and overall calculation by leaders, which necessitates the plans on symbolic communications over the course of a year to advance a particular strategic objective (Nye, 2005). That follows the emphasis of both Clausewitz and Sun Tzu on unpredictability and interconnection of generals' variables and factors and virtues. Last but not least, smart power strategy includes international development aid and global governance mechanism, regardless of whether the latter one is performed based on the national-interest calculation or not. It is because solving today's global problems necessitate smart power-a judicious blend of the other two powers because the nature of today's international challenges and unconventional threats-fragile states, humanitarian crisis, chronic poverty, dysfunctional governance mechanism and institutions and so forth-attests to the urgent diplomatic significance and implications for smart power strategy. That indirectly develops the definition of strength from Clausewitz and Sun Tzu who focused less on one important part of it: quality of governance and of diplomacy.

\section{Pragmatic Evaluation on Implementation of Smart Power Strategy by the US, China and India 3.1. Accomplishments and Dilemma of US Smart Power and its Lessons}

Albeit in some ways it is of much complexity to to make an accurate assessment and a quantification of the power of a state in an absolutely objective way owning to limited documents and resources, it seems that few strategists and analysts would refute that the United States, nowadays or even in the foreseeable future, will remain the strongest military and economic superpower on the world stage (Zhang, 2004). It is fair to say that Zhang Xiaoming's proposition and conclusion omit the law of rise and fall or at least spiral trajectory of a state actor (unless every policy, domestic and diplomatic alike, is based on rational, pragmatic, 
targeted decisions which generate maximum perfect ramifications), including a hegemonic power, it is worth carefully discovering the root causes of US dominant position over a long period. Suzanne Nossel argues that decision-makers of state actors should advance a foreign policy that renders smart use of power to promote U.S. interests through a stable grid of allies, institutions, and norms. "They must define an agenda that marshals all available sources of power and then apply it in bold yet practical ways to counter threats and capture opportunities" (Nossel, 2004: 132). It is fair to observe that at certain moments, the United States highlight the use of all variables: especially American-style democracy and values through non-governmental as well as governmental channels as a leverage to enhance infiltration of their influence worldwide (Li, 2006). Part of successful cases has been observed that US popular culture products sweep every corner of the globe; US education and research institutions attract the largest proportion of international students and researchers so far, and "America holds the world's most authoritative academic standards and most of the academic achievements" (Yan, 2010: 139). When it comes to quantifying the dissemination of US soft power, the US represents the production of $75 \%$ of the world's TV programmes, with the example of the broadcast of NBA programmes in 42 languages globally with 750-million audience (Li, 2006). Briefly speaking, US soft power resources have infiltrated into considerable aspects of the international society.

When it comes to the nexus between the public and smart power strategy, a positive correlation between them tends to occur. Historically, over the course of the Second World War, the then US President Franklin Roosevelt rallied an isolationist U.S. public to combat the military force of Nazi Germany by offering a postwar vision beyond defeating fascism. President Franklin Roosevelt pledged that a generation's sacrifice would yield military victory and institutions and alliances in the prevention and preparations of future potential war. Nowadays, the combination of stronger alliances (hard power in relative terms) and more effective international institutions (soft power in relative terms) can likewise overcome apprehension of the public and show a sense of legitimacy and international reputation. It can be concluded that smart investments in smart power strategy will yield lasting results and liberal internationalism can galvanise both the US public and the international community.

Theoretically speaking, following Sun Tzu and Clausewitz's arguments on unpredictability of environment and interconnection of exogenous factors, it can be observed that the international structures and international arena grow more unpredictable and intertwined with multiple variables, implicit and explicit alike; thus, only by utilising more efficient and effective methodology of exercising its smart power strategy can decision-makers be driven to pragmatically create opportunities for action where idealism and realism intersect in pursuit of their goals in ways that reinforce, but not degrade, US power" (Nossel, 2004).

Unfortunately, it is worth pointing out that misusing US strong hard power is detrimental to its could-be smart power strategy. For instance, in 2003, the US launched Iraq War on the basis of its strong hard power, even in defiance of massive denouncement and recriminations from the international community in the absence of authorisation of the United Nations Security Council (Zhang, 2004). Owing to the failure of conceptualising and dismissing the strategic necessity of smart power strategy and sticking to narrow self-interest, most of the world who viewed the US seemingly as a rightful example in the postwar period regard it as an oppressor, hungry for petroleum and hegemony at present. Its duality-oriented commitment to controversial democratisation in services of the US interests-advanced merely after other justifications for US intervention in Iraq had been engulfed into atrophy. At the domestic level, its manipulation of the evidence on Iraqi weapons programmes, its denial of basic rights to prisoners at Guantanamo Bay made the US administration's rhetoric of freedom seem undesirably hypocritical (Nossel, 2004). Owning to the strategically imbecilic ignorance and dismissal of adopting smart power strategy by undermining alliances, international institutions, and US credibility, the then Bush administration triggered a cycle that is depleting U.S. power. Not taking global cooperation seriously has encouraged distrust of U.S. motives, hampering U.S. effectiveness in Iraq. "The pernicious result is that so-called spread of liberal democracy are becoming associated, at least in the volatile Middle East, with a violent and unwanted occupation" (Nossel, 2004: 135). As a result, the prerequisite of using smart power becomes nearly hollowed, owning to a unilateral US foreign policy hijacked by anarchic domestic structure.

In the early $21^{\text {st }}$ century, global anti-Americanism elevated to an unprecedented height, causing negative effects on US soft power (Yan, 2010). The example of European elites' resistance to infiltration of US culture that they regard as a threat to the cultural identity of the European society can be a reinforcement of Yang's observation. Political and cultural elites unveil deep criticism of US cultural hegemony (Yan, 2010). In August 2008, an editor of a leading newspaper in Saudi Arabia pointed out that US culture without acquiring any knowledge of Muslim cultural customs and Islamic Civilisation was such ignorance causing a clash between Islamic Civilisation and Occidental Civilisation (Yan, 2010).

Beyond the failed case of the Iraq War, in 2018, the Trump Administration unilaterally launched an accelerating trade war against Chinese enterprises based on its strong hard power in defiance of massive opposition from the international prestigious Economists and business community and even US Chamber of Commerce (see AmCham Shanghai Report, 2018 \& 2019 ; China Daily, 2018 \& 2019). In 2020, the US accused China of spreading COVID-19 without providing empirical, verifiable evidence; that 
engenders widespread refusal to that unfairly politicised accusation among many international immunologists, medical professionals and international-relations intellectuals, whose allegations are deleterious to the international credibility and international standing of the United States as a unipolar power in relative terms in a world of multipolarity (Zhao, 2021). It can also be theoretically deduced that Trump's Team-launching tariffs-based trade war and technology war against Chinese enterprises and even European partners and Biden's Team inheriting the tough strategic position from his predecessor against Chinese counterparts inevitably generate dilemma of US smart power within the Chinese public. Moreover, it can also be seriously observed that similar to the dilemma of unilateral military action in Iraq, disorganised military evacuation from Afghanistan that engenders volatility and messiness of the Middle East region make US soft power fall into an unanticipated quagmire where hard power was on terror has not ultimately exterminated and obliterated transnational extremism and terrorism.

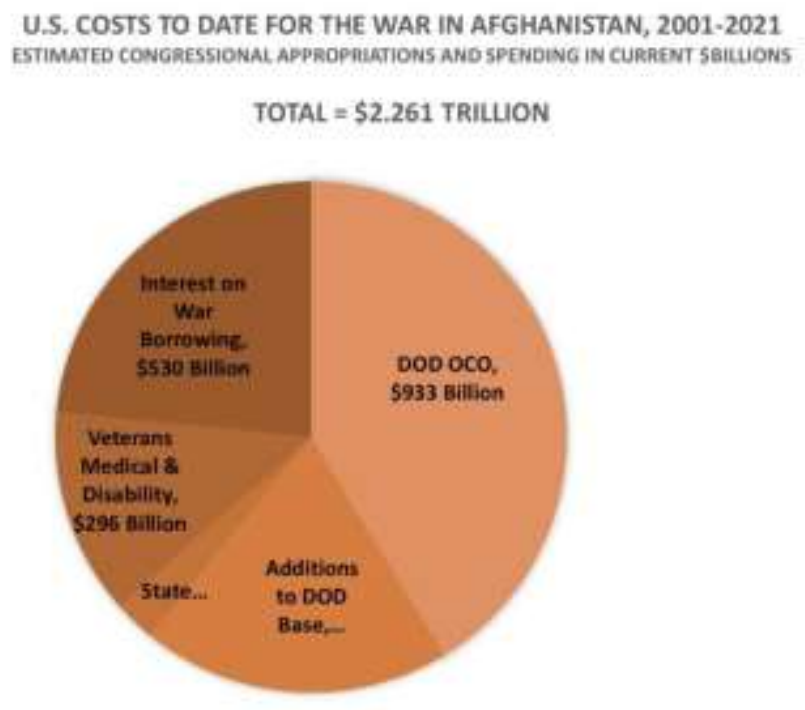

Note: From U.S. Costs to Date for the War in Afghanistan, 2001-2021", by Watson Institute for International and Public Affairs of Brown University, 2021. Human and Budgetary Costs to Date of the U.S. War in Afghanistan, p.1. Copyright 2021 by Watson Institute for International and Public Affairs of Brown University. Permission not sought.

The hermeneutic inheritance from Clausewitz's strategy and Sun Tzu's strategy facilitate analysts and strategists to critically deconstruct and evaluate the example of the US hard power, and it can be recognised that US comparative advantage should come not from weapon or military but rather from farsighted strategy, sophisticated leadership and maximum professionalism. However, the vacuum of smart-power strategy generates the unanticipated creation of sources of frictions, turning alliances and partnerships into antagonistic structures and undermining valuable diplomatic tools that smart power strategy necessitates.

\subsection{Smart Power Strategy and Peaceful Rise of China}

Not only does smart power reflect a country's holistic national strength, but more importantly, it can demonstrate a consequential catalytic role in international exchanges in a multipolar world of constant changes, economically, militarily and strategically. As China grows from a third largest economic power to a second-largest economic entity, the operation of Chinaworld cultural exchanges and the nature and scope of China's international standing are amplifying, correspondingly. For example, the Year of Chinese Culture has enabled the Chinese and French demographics to engage with each other at "zero distance" and stimulated the French population to show around Chinese cultural exhibitions that are an inseparable component of Chinese soft power (Li, 2006). Of course, that kind of cultural-exchange situation was of much high frequency during the facilitation of then French President Jacques Chirac (1995-2007), who was a famous China-studies connoisseur. Currently, French President Emmanuel Macron's visit to China in January of 2018 and in November of 2019 helps deepen the cultural understandings of the sustainable, durable Han Chinese Civilisation (Lau, 2019; Tan, 2018). French President Emmanuel Macron's visit to China with a tour of the Terracotta Warriors, which is symbolic of cultural power from the Qin Dynasty of the ancient Chinese period, is indirectly indicative of Chinese soft power sustainability and dynamism (O'Donnell, 2018). It is reported that Philippe Le Corre, a fellow at the Carnegie Endowment for International Peace who specialises in China-EU relations, argues that Macron's oriental route to China was as much a 'win-win' as it could be, i.e. the non-confrontational strategic partnership 
between France and China and France's objective of playing a non-negligible role at the EU level (Lau, 2019). Le Corre's argument in some cases shows that both France and China, as two important civilisational entities in the Western Hemisphere and Oriental Hemisphere, respectively attempt to launch their willingness to achieve mutual but differentiated national objectives through the means of cultural diplomacy that is part of smart power strategy in services of their national objectives.

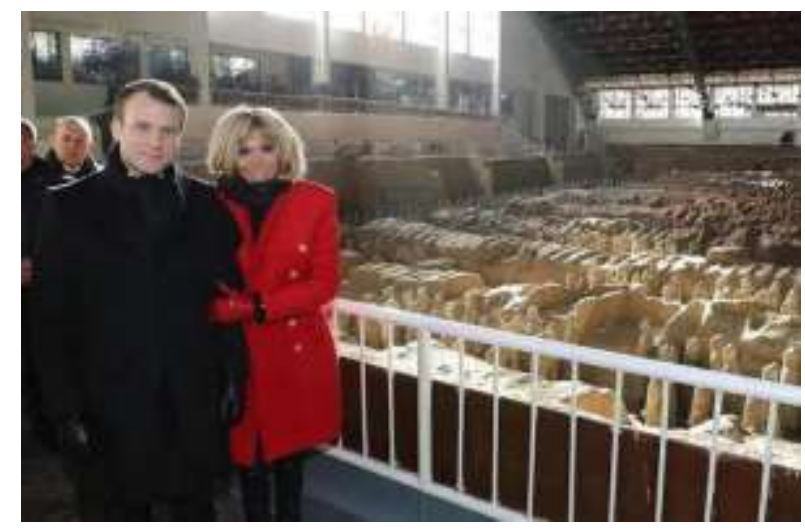

Note: From "French President Emmanuel Macron kicked off a three-day visit to China with a tour of the famous Terracotta Warriors along with wife Brigitte Macron earlier today" by B. O'Donnell, PHOTOS: French President Emmanuel Macron Visits China, https://www.thatsmags.com/china/post/21987/photos-french-president-emmanuel-macron-visits-china, Copyright 2018 by B.O'Donnell. Permission not sought.

Smart diplomatic strategies and diplomatic decision-making can, to a large degree, help to obtain worldwide international acknowledgement and wisely and naturally externalise their legitimacy and moral authority (Shi, 2009). In other words, they can meanwhile effectively ameliorate a country's international role, enhance its ability to command international agenda and thus greatly amplify its international influence by virtue of smart power. On the contrary, irrational, non-pragmatic, non-smart diplomatic strategies and decision-making may pose a substantial flow to a country's international status and reputation or even cause a crisis, disputes and even conflicts (Shi, 2009). China's diplomatic strategy witnessed crucial changes recently in that softpower of national culture that generates public diplomacy, which aimed at exposing China to the world concerning China's state of affairs, policies and Chinese civilisation, creating a more objective milieu of standpoint and prospects and advancing China's international place and standing (Yu, 2010). It can be acknowledged that wearing Chinese Tang costume, drinking Chinese herbal tea and even acquiring ancient Chinese vernacular and poems have been on a track of becoming a global phenomenon; "Chinese element" is gradually becoming a symbol of trend in areas of fashion design, painting, architecture and industrial design ( $\mathrm{Li}$, 2006). To some extent, to China, unconventional people-centric public diplomacy will be a supplementary bifurcation if conventional state-centric diplomacy, or interstate diplomacy, cannot play a role of lubricant in complex international affairs civilisational exchanges. In particular, under the grand circumstance of the in-depth development of globalisation, countries worldwide are more interwoven in terms of their raison d'état. Diversified ideologies and social systems give rise to misunderstandings and suspicion of the public abroad. Under this circumstance, the soaring economic globalisation internationalised domestic issues and vice versa enforce relevant state actors or individuals to relinquish the obsolete conception of decoupling domestic issues of external ones ( $\mathrm{Yu}, 2010)$. China's perception of perennial peaceful development road and building harmonious world are generally acknowledged worldwide, albeit suspicions and miscalculations remain (Yu, 2010).

It can be found that China's growing highlights on the role of smart power can be deduced from, but not limited to, three major operations of grand strategy, which are not merely conducive to China's global position and but also to world's development, i.e. a) global expansion of establishment of Confucius Institutes, b) sustainable development in transnational cooperation against climate change; c) profound promotion of controlling the global COVID-19 pandemic.

To start with, from the cultural-strategy perspectives, the emerging inter-regional and transnational establishment of Confucius Institutes contributes to the noticeable dissemination of Chinese smart power. Upon the crucial experience of numerous international civilisational entities from the European Continent, such as the UK, France, Germany and Spain, in the advancement of their national languages and cultures regionally and even globally, China commenced its own exploration in 2004 through Confucius Institutes in promotion of the Chinese culture at an international level (Li, 2017; Bao, 2021). Albeit in most ways the massive establishment of Confucius Institutes at a transnational level causes unanticipated politicised misinterpretations and misconceptions, never could their indelible cultural contributions to the dissemination of Chinese culture be negligible (Shi, 2016). Statistically speaking, Recent years have witnessed an gradual increase in the spread of Confucius Institutes (nearly 440 Confucius Institutes and 646 Confucius Classes worldwide at the inception of 2014) since the opening of the original Confucius Institute in the Republic of Korea in 2004 (Kukharenko \& Klyuchanskaya, 2014). Then, 1073 Confucius classrooms and 511 
Confucius Institutes in nearly 140 nations have made Confucius Institutes play a crucial role to bridge civilisational exchange (Li, 2017; Bao, 2021). In Ireland, Confucius Institutes have penetrated almost all the educational institutions: over 5,000 students from the primary and secondary schools participated in Chinese-language lessons annually (Li, 2017). Beyond developed countries and regions, by the end of 2013, 37 Confucius Institutes and 10 Confucius classes in Africa had been set up in 31 African countries, followed by the assistance of 360,000 Chinese technical experts and professionals to Africa (He, 2017). The abovementioned statistics can signify growing recognition and acceptance of Confucianism-themed Han Chinese Civilisations worldwide and Chinese smart power strategy indirectly follows the strategic significance of culture Clausewitz highlighted and the importance of strategically winning without fighting that Sun Tzu emphasised though the establishments of Confucius Institutes have nothing to do with war issues but rather are more relevant to inter-civilisational communication in services of a better international role and status.

Second, from the international-regulation perspectives, China attempts to utilise this international issue that is also part of its national interest through smart-power-oriented diplomacy because climate change concerns human existence and development (Kong, 2020; IPCC SREX, 2012). The moral obligation to mitigate climate change is partly symbolic of smart power. The global climate crisis can be defined as one of the most massive unconventional threats confronting this shared plant. According to observation data, global climate over centuries has been experiencing warming-characterised alteration (IPCC AR5, 2013; Kong, 2020). Ever since the Industrial Revolution commenced over two centuries ago, increasing amounts of carbon-based fossil fuels, petroleum, natural gas and coal have been burned. The by-products of combustible, toxic, carcinogenic materials and certain pollutants such as sulfur oxides, nitrous oxides, hydrofluorocarbons and chlorofluorocarbons, etc., are being dumped and heated, which generate deleterious, poisonous chemical components detrimental to the shared planet. Thus effectively confronting this unprecedented unconventional, transnational global climate crisis necessitates an unprecedented level of smartpower-oriented international cooperation, which can be viewed as a type of new culture strategy or reputation strategy. Gao Yun, at the Department of Technology and Climate Change of China Meteorological Administration, observes that the Paris Climate Change Conference eventfully wrapped up with the Paris Climate Accord adopted on 13 December, 2015, a kind of transnational treaty by which most economic powers have legal obligations to abide (Gao, 2016). By participating in IPCC assessments and conducting national climate change assessments, China has been raising awareness over this urgent climate crisis and China's proactive participation in the Paris Climate Change Conference indicates the rationality and necessity of global warming response by China at a strategic level and China's long-term commitment to the genuine ecological development programme for building a low-carbon and climate-resilient global community. "China pledges to peak carbon emissions by 2030 and reduce the emission of carbon dioxide per unit of GDP by $60 \%-65 \%$ by 2030 " (Gao, 2016: 236). All of these commitments and strategic decision-making behaviours characterise the smart power strategy of distinct, different Chinese characteristics and of being compatible with international structure and treaty that may better serve its national interests not through the means of hard power.

Third, from the perspective of rebuilding global public health governance mechanism, whether the global COVID-19 pandemic can be efficiently controlled and mitigated is also an exemplification of smart power strategy as the outbreak and spread of this pandemic has posed severe, eminent threats to public health security, economic globalisation as well as global governance. Zhao Yongyue, Professor and Dean at School of International Governance Innovation at Guandong University of Foreign Studies, points out that in compliance with the prediction by the International Monetary Fund, the global economy will shrink by $4.4 \%$ and developed countries by $5.5 \%$ and emerging markets and developing economies by $3.3 \%$, whose scale of devastating impacts are predicted to far outweigh that of the international crisis of capitalism from 2008 to 2009 (Zhao, 2021). Geo-economically speaking, "according to recent official statistics, in the first quarter of 2020, Vietnam registered a growth rate of 3.83\%, Indonesia 2.97\%, Malaysia 0.7\%, the Philippines $-0.2 \%$, Thailand, $-1.8 \%$, and Singapore $-2.2 \%$ " (Wang, 2020:15). On the other hand, "at present, COVID-19 pandemic is accelerating the periodical changes of the global economic situation, thus bringing opportunities to a new wave of economic globalisation" (Zhao, 2021: 30). Since the outbreak, China has done a noticeably satisfactory performance in taking the strictest comprehensive measures to control the pandemic to keep the damage to social and economic development to a minimum. Thanks to effective control of the pandemic in the China Market coupled with international cooperation between ASEAN members and China under the support of top leaders and medical professionals has enabled East Asian members to be pioneering in revitalising their economic growth and resuming production (Hao, 2020). In terms of vaccine production, in accordance with China Economic Weekly (2021), on 31 December 2020, Chinese officials announced at a press conference that the National Medical Products Administration (NMPA) had granted conditional approval to domestically-produced inactivated vaccines against COVID-19. The vaccines have met both the WHO and NMPA standards in terms of efficacy. The Philippines received the second batch of Chinese CoronaVac Vaccines at an international level on 11 April 2021. Thailand, on 17 May 2021, received a batch of Sinovac COVID-19 vaccines donated by China. (China Report ASEAN, 2021). At the multilateral level, China is in close communication and cooperation with the WHO and GAVI Alliance or the Global Alliance for Vaccines and Immunisation. China has joined COVAX as well as the Access to COVID-19 Tools (ACT) Accelerator Initiative 
(Zhao, 2021). Both COVAX and ACT aim at developing and providing life-saving resources to battle COVID-19 by bringing together governments, pharmaceutical companies and society (Zhao, 2021). In terms of information sharing, China shared critical information about the COVID-19, the genome sequence, as early as January 2020 with the rest of the world (Zhao, 2021). The above-mentioned diplomatic decision and commitment are matched with the principle of new culture orientation of smart power strategy that morality and international obligation enhance national strength and international role even in the world matrix that includes diversification of national interests.

The philosophical merits of "winning without engaging any war as a kind of optimum strategy" from The Art of War theoretically facilitate the Chinese decision-makers to adhere to prioritise sustainable development and necessary international cooperation instead of zero-sum game in avoidance of unnecessary confrontational paradigms or strategic miscalculations unless China's raison d'état (i.e. national interest) is in absolute terms at stake in the face of pessimistic exogenous pressure from the international arena. The advancement of information technologies has greatly facilitated the transnational public to dialectically compartmentalise and conceptualise the values, national spirit and quality of demographics of various state actors, providing unprecedented favourable conditions for smart power to play its role. The rise of the standing and influence of smart power in the overall national strength is becoming an important manifestation of international competition (Li, 2006).

\subsection{What Merits and Lessons Can be Learned from India's Example of Smart Power Strategy?}

After much analysis of pragmatism, predictability and also the duality of performing smart power strategy by the United States and China as two economic juggernauts thus far, it is necessary to notice that a calculated, organic combination between rational-based hard power and flexible soft power can make a decisive difference in influencing geopolitical and geo-economic structure. In some cases, if one of the two countries, potentially as well as alternative critical members in a rising Asia-Pacific region, conducts rational decisions at domestic and international levels in pursuit of winning and superiority without being irrationally engulfed into needless war and keeping perpetual psychological and strategic overall planning and advantageous position in accordance with the variables that both Clausewitz and Sun Tzu hypothesised, smart power strategy will be perfectly generating desirable results that well serve national interest and international role.

The world structure has been changing from a bipolar system to a multipolar system. Therefore, it has to be objectively recognised that in today's world, the pivot has been gradually metastasising from the Occidental Continent to Oriental Continent and Asia is rising at a speedy rate. In addition to China, India, another crucial developing country in Asia, is at its crossroads of most intricacy (Mishra, 2018). Vivek Mishra, Assistant Professor of International Relations at Netaji Institute for Asian Studies, argues that Multifaceted conundrums encumber india's diplomatic strategy and decisions at the geopolitical and geostrategic levels are far more complicated than were in the bipolar system. The vital questions of how India chooses to hedge with stakeholders both regionally and inter-regionally on the basis of smart power strategy of distinctive Indian characteristics and whether the diplomatic strategy in a different way does follow the strategic principles that Clausewitz and Sun Tzu or not are the underlying international agenda for Indian decision-makers. To be sure, smart-power elements of India as an indispensable international actor of BRICS in South Asia can comparably be abstractly inherited as India's civilisational history has rendered the role of India with distinct civilisational and value system from the technological, educational and sociocultural perspectives.

When it comes to the technological perspectives, the smart power of India is implemented by the grace of an affluent, solid technological foundation. Science and technology were advanced in ancient India thanks to India's preference for technology, mathematics and astronomy that Industrial Revolution did promote. As a result of chronological technological advancement and breakthroughs, India has become the world's third-largest power of science and technology and the second-largest country of software production and export, whose products are proportionate of much popularity in the American Continent European Continent, and elsewhere. At the domestic level, the software industry contributes more than $7.5 \%$ of the total GDP growth for Indian. At the international level, in the global software development market, the statistics of Indian software represent a share of $16.7 \%$. Among the fortune 500, 160 large multinational corporations cannot be decoupled with the supply of Indian software (Shi, 2009). In compliance with the strategic principle proposed by Clausewitz and Sun Tzu, Indian software-producing capabilities have significantly kept-and can continue to keep India at a competitive, advantageous position on the track of being superior over other economic entities or states actors.

Regarding educational perspectives, India's competitive advantage for implementing a smart power strategy partly lies in its strategic pivot to cutting-edge education and state-of-the-art professional training that must empower national strength. Successive Indian governments since independence have been conscious that social progress and steadfast development of strategic investment in genuine education and professional training to eradicate adult illiteracy are unquestionable inseparable. The investment of $3.68 \%$ of GDP in Indian education- 0.81 percentage higher than that of China-is the reinforcement of their strategic awareness of soft power at the governmental level $(\mathrm{Wu}, 2010)$. According to the 2001 census, the over-seven-year literacy rate has reached 65.38 percentage points, thanks to 520, 000 primary schools, 130,000 secondary schools, 5246 technological academies, and 3.5 million students in high schools rank the third largest on the world stage $(\mathrm{Wu}, 2010)$. 
Furthermore, the advancement of competitive Indian higher education cannot be separated from the timely establishment of approximately 200 research-based universities, 6,000 institutions of professional mentoring at a higher level and 2,000 research institutions, which produce proportionately one million engineering graduates annually in comparison with the statistics in the United States or the European Continent: no more than 100,000. "The Indian Academy of Sciences, India Institute of Technology Mumbai, and so forth are all places where the US Silicon Valley comes to grab talents" (Shi, 2009: 43). In compliance with the strategic principle proposed by Clausewitz and Sun Tzu, pioneering multidimensional investment in education and professional training have comparably facilitated India to strategically identify and strengthen its own condition for utilising smart power in the face of multiple potential challenges from other state actors or international actors.

When it comes to the sociocultural perspectives, it can be argued that the smart power of India rests from India's honouring mutual learning from something superior for the sake of maximum competitiveness on the world stage without abandoning national culture and national identity. On the one hand, it has been observed that one of India's competitive disadvantages lies in agriculture and manufacturing that must generate a new way of national economic development. Under this circumstance, India has established its own "Silicon Valley" in Bangalore and has generated considerable accomplishments. On the other hand, Indians hold faith that Indian civilisation is the cradle of the world's profound civilisations. "For Indian Bollywood movies not only are popular in the South Asian sub-continent, but have a considerable influence in the Gulf, the Middle East, Africa, Russia, China, Far East, North America, Europe, etc." (Shi, 2009: 44). In compliance with the strategic principle proposed by Clausewitz, who had advanced that primary of culture and recognised war-fighting strategy as a text of moral and physical forces (Kaura, 2021), maintaining a good attitude of mutual learning for the national role and collective self-esteem and strengthening cultural elements have largely stimulated India to strategically amplifies its own conditions for utilising smart power. That strategic decision and implementation are compatible with the conception of Russell Weigley, who underscored the implications of cultural dimensions of strategic calculations (Weigley, 1960; Kaura, 2021).

The question of whether India perfectly carries out smart-power-based foreign policy requires comprehensive examination. From the historical perspective, it is observed that during the Cold War-based bipolar period, India chose to eschew the potential alliances with one of the two confronting blocs and instead proposed non-alignment, Asia-African unity and disarmament (Shi, 2009). To some extent, this kind of rational, pragmatic, non-alignment diplomatic strategy on the basis of India's national interest and, in some cases India's geopolitical calculation has galvanised India to rise as an indispensable power in the Third World. Through the smart policy of non-alignment, cooperative synergy in the Third World, national self-reliance and non-proliferation of weapons of mass destruction, India's regional leadership sought to prioritise realism and pragmatism as its core (Kaura, 2021). In the $21^{\text {st }}$ century, India and China joined in the developing-member-group-based BRICS as one of the fastest-growing emerging markets, nearly on par with the markets of the Western Hemisphere, which makes China become the India's second trading partner and India becomes the ninth trading partner for China (Shi, 2009). These diplomatic achievements were gained not merely through India's appropriate foreign policies but more crucially with rational-based diplomatic, strategic calculation on options to best serve India's national interest at a nearly nominal expense.

Every coin has two sides. India's implementation of smart power of distinctive Indian characteristics causes blemishes owning to its domestic problems and for social and historical reasons. India has been following the 'neighbourhood policy' since the prime ministership of Jawaharlal Nehru. However, India's strategic neighbourhood diplomacy has not necessarily generated satisfactory results owning to its yet-to-be perfectly-designed smart power strategies and mismatch between domestic investments in societal sectors and growing non-pragmatic diplomatic strategies from the Realpolitik perspectives only, which is not in a genuine fit with a world of multipolarisation any longer. Scarcely has India made a substantial breakthrough in its neighbourhood diplomacy in South Asia in spite of having conducted impressive global diplomacy (Bao, 2021). Vinay Kaura (2021) highlights that India repudiates and eschews the classical notions of balance of power at an international level and sticks to the Non-Alignment Movement (to some extent, begrudgingly) whilst there is an obvious phenomenon of India's attempts to maximising influence in the South-Asia region. As a result, India was on the one hand resolutely against intervention by major powers in the internal affairs of the weaker ones; on the other hand, within the subcontinent, 'it had to perform the function or provide security to the smaller nations and their regimes' (Mishra, 2018). This duality-oriented neighbourhood policy makes India itself contradicted its belief by constantly meddling in the internal affairs of the economically disadvantageous powers inside the South Asia region, which causes the transformation of the advantageous condition for smart power strategy into the disadvantageous condition and international credibility dilemma. George. K. Tanham pronounced that India had a strategic culture deficiency in the back of its growing geopolitical objectives (Tanham, 1992). It can be hypothesised that India's heterogeneity of culture, historical legacy and the non-alignment-based diplomatic strategy halt the proliferation of maximum rational deliberation on smart power strategy, which then might have contributed to classical defensive strategic responses of hard power to multiple challenges from the perspectives of conventional national security (Tanham, 1992; Kaura, 2021). The cases of cross-border terrorism and confrontation in Kashmir between India and Pakistan, border disputes across Lipulekh with Nepal and Dokhlam with China and Bhutanhave, made India's foreign policy unfavourable in South Asia (Ayres, 2020, Bao, 2021). 
Moreover, India's civilisational dynamism and flexibility, which is translated into part of its smart power strategy, does not offset its mismanagement and miscalculation on the Kashmir-relevant territorial issue with China, whose civilisation is chronologically uninterrupted. The advantageous conditions for Indian smart power are dwindling, correspondingly. Theoretically speaking, if India's conditions for perfecting smart power requires strategic renewal, then taking more comparable measures of regional integration and international cooperation measures like the Bangladesh-Bhutan-India-Nepal (BBIN) Corridor, Bay of Bengweal Initiative for Multi-Sectoral, Technical and Economic Cooperation (BIMSTEC), and South Asia Association for Regional Cooperation (SAARC) and so forth is of much necessity and urgency, politically, economically, and strategically.

Above all, it can be argued that India is endowed with the natural conditions for its smart power resources and India has been observed to try to create more conditions for adopting a smart power strategy that is compatible with Indian characteristics; however, the non-virtuous restrictive variables on well-designed implementation of its soft power have generated negative consequences and impeded its international role in an international arena of no bipolar system.

\section{Conclusion}

As a result of most case studies of US, China and India and extensive analysis of nature, structure, and implementation of smart power strategy, this paper concludes that smart power strategy bears historical and intellectual inheritance from Clausewitz's strategic concept and Sun Tzu's strategic concept, which has profound hermeneutic and contemporary implications for today's complex international arena of power co-opetition (competition and cooperation combined). The philosophical conceptions of strategic winning without any fight and keep strategic and psychological dominance against the rivals and aggressors from The Art of War are historically and theoretically synergistic with the philosophical conception of grand strategy and consolidation of power from On War, albeit in some ways their disparity in historical background and socio-cultural context.

In addition, it has been observed that in-depth adoption and implementation of smart power strategy is consistent with sound, fair and sustained development strategy, which will be more effective, comprehensive, and multidimensional in services of taking leading positions in a complex international arena of constant changes. On the one hand, it is worth abstractly learning the reasons for smart power from US examples of the part of positive elements: e.g. competitive higher education system and advancement of science and technology; on the other hand, there is no empirical reason--at a strategic level--for not being critical of the abuse of hard power and dismissal to benign implementation of smart power: war in volatile the Middle East, unilateral liberal democratisation, and strategically ill-advised trade war and technology war against certain state actors and nonstate actors with disregarding their fundamental interests. Furthermore, China and India as two crucial members of BRICS have been amplifying their effort to utilise the positive role of smart power in cultural understandings of historical experience and civilisational exchanges.

These above-mentioned cases can exemplify that the definition of strength and power generates no fixed uniformity. Instead, it can be observed that the indispensable necessity and significance of seriously adopting and implementing smart power are more pronounced in today's international arena comprising of rule-making, leadership, partnership and competition. When emphasising the importance of soft power in foreign policy, one cannot ignore the necessary, appropriate use of hard power because strong hard power, to some extent, lays a solid foundation and provide the condition of strength for better strategic implementation of soft power because a country without holding hard power will put itself into security dilemma. However, if an international actor cannot well coordinate strategic international engagement and relationship with hard power, it will suffer from credibility and influence deficiency that cause credibility and leadership dilemma. Ultimately, the international society should plan to re-adopt the new-era implications of smart power strategy as well as its potential links to the nature and scope of seeking minimum strategic confrontation and maximum cooperation strategically.

\section{References}

[1] AmCham Shanghai Statement on Tariff Increase. (2019, May10). Amcham Shanghai Magazine https://www.amchamshanghai.org/en/article/amcham-shanghai-statement-tariff-increase

[2] Ayres, A. (2020). Conflict between India and Pakistan. https://www.cfr.org/global-conflict-tracker/conflict/conflict-between-india-andpakistan.

[3] Bao, L.J. (2021). Trilateral Relations among China, Nepal and India: Opportunities, Challenges and Prospects. Journal of Humanities and Social Sciences Studies, 3(7), 5-14.

[4] ----- (2021). Confucianism and Philosophy of a Shared-Future Global Community in an Inter-civilisational World Order: Comparative Analysis of Their Relationships and Prospects. Journal of Humanities and Social Sciences Studies, 3(8), 1-9.

[5] China's Speed in Vaccine Development. (2021). China Economic Weekly, p.1

[6] Crawford, N. C. \& Lutz. C. (2021, April15). Human and Budgetary Costs to Date of the U.S. War in Afghanistan.https://watson.brown.edu/costsofwar/files/cow/imce/figures/2021/Human\%20and\%20Budgetary\%20Costs\%20of\%20Afghan\% 20War\%2C\%202001-2021.pdf

[7] Diane Contu's Interview with Joseph Nye on Smart Power. (2008, November). Harvard Business Review. https://hbr.org/2008/11/smartpower

[8] Clausewitz, C. (1874). On War, In Graham. J.J. (trans). https://www.fulltextarchive.com/pdfs/On-War.pdf 
[9] Gao, Y. (2016). China's Response to Climate Change Issues after Paris Climate Change Conference. Advances in Climate Change Research, 7, 235-240.

[10] Hao, N. (2020). Rising to the Challenge: China's AESAN Economic Zones Wrestle in the Shadow of the China-U.S. Clash and COVID-19 Pandemic. China Report ASEAN, 7, 60-63.

[11] He, W.P. (2017). Rethinking China's Soft Power Building in Africa. International Understanding, 2, 1-10.

[12] Hudson, V. M. (1997). "Culture and Foreign Policy: Developing a Research Agenda", Culture and Foreign Policy, Lynne Rienner Publishers.

[13] Impact of U.S. and Chinese Tariffs on American Companies in China. (2018, September19). Amcham Shanghai Magazine. https://www.amcham-shanghai.org/sites/default/files/2018-09/2018\%20U.S.-China\%20tariff\%20report.pdf

[14] IPCC SREX. (2012). Managing the Risks of Extreme Events and Disasters to Advance Climate Change Adaption. Cambridge University Press.

[15] IPCC AR5. (2013). Intergovernmental Panel on Climate Change Climate Change 2013 Fifth Assessment Report (AR5). Cambridge University Press.

[16] Kaura, V. (2021). The Strategic Culture of India's 'Third Republic'. Rising Asia Journal, 1(2), 273-299.

[17] Keohane, R.O. \& Nye, J. S., Jr. (1998). 'Power and Interdependence in the Information Age'. Foreign Affairs, 77(5), 81-94. https://www.jstor.org/stable/20049052

[18] Kissinger, H. (2011). On China. Penguin Group.

[19] Kong, F. (2020). China's Climate Change Response in the Context of Global Change: from Domain Response to Mitigation and Adaption then to Scientific and Technological Progress. Journal of Landscape Research, 12(1), 65-72.

[20] Kornberger, M. (2013). Clausewitz: On Strategy. Business History, 55(7), 1058-1073. https://www.researchgate.net/publication/262858916 Clausewitz On strategy

[21] Kukharenko \& Klyuchanskaya. (2014). China's Soft Power. International Understanding, 4, 67-68.

[22] Lau, Stuart. (2019, November7). French President Emmanuel Macron's visit to China was a success, but more could have been achieved, experts say. South China Morning Post. https://ph.news.yahoo.com/french-president-emmanuel-macron-visit-052429374.html

[23] Li, Q. (2017). A Future for EU Foreign Policy: Is Soft Power Enough?. English on Campus, 39, 254-255.

[24] Li, J. (2006). Soft Power Building and China's Peaceful Development. China International Studies, 4, 164-179.

[25] ------ (2017). The Globalization Pace of Confucius Institutes. Voice of Friendship, 188, 21-25.

[26] Mishra, V. (2018, June14). Strategic Hedging through Foreign Policy: Exploring India's Options, https://thegeopolitics.com/strategichedging-through-foreign-policy-exploring-indias-options/

[27] Morgenthau, H.J. (1956). Politics among Nations, the Struggle for Power and Peace. Alfred A. Knopf.

[28] Nossel, S. (2004). Smart Power. Foreign Affairs, 8(3) 2, 131-142. http://www.democracyarsenal.org/SmartPowerFA.pdf

[29] Nye, J.S., Jr. (2009) Get Smart: Combining Hard and Soft Power. Foreign Affairs, 88(4), 160-163.

[30] ---- (2005). Soft Power: The Means to Success in World Politics. PublicAffairs.

[31] O’Donnell, B. (2018, January8). PHOTOS: French President Emmanuel Macron Visits China, https://www.thatsmags.com/china/post/21987/photos-french-president-emmanuel-macron-visits-china

[32] Philippines Receives More Sinovac Vaccines Purchased from China. (2021). China Report ASEAN, 5, 7

[33] Sun, T.. (2002). The Art of War. In John Minford (trans). New York: Viking.

[34] Shi, H.Y. (2009). The Rise of Soft Power in India's Rise. China International Studies, pp. 42-57.

[35] Shi, Z.Z. (2016). A Study on the Current Status of China's Cultural Soft Power. Academics, 6, 268-272.

[36] Tanham, G. (1992). Indian Strategic Thought: An Interpretive Essay. RAND.

[37] Tan, H.L. (2018, January10). Macron's China Visit Points to Beijing Shifting Relationship with Europe. CNBC.https://www.cnbc.com/2018/01/10/macrons-china-visit-points-to-beijings-shifting-relationship-with-europe.html

[38] Thailand Receives China-donated COVID-19 Vaccines. (2021). China Report ASEAN, pp.6

[39] US unilateral tariffs against China undermine rule-based international trade: Stiglitz. (2018, April13). China Daily. https://global.chinadaily.com.cn/a/201804/13/WS5ad062d2a3105cdcf651828c.html

[40] US pundits call for resolution of trade dispute. (2019, May30). China Daily. http://www.chinadaily.com.cn/a/201905/30/WS5cefecdea3104842260bebfc.html

[41] USC Centre on Public Diplomacy. (2019). The Soft Power 30: A Global Ranking of Soft Power. https://softpower30.com/wpcontent/uploads/2019/10/The-Soft-Power-30-Report-2019-1.pdf.

[42] Wang, Q. (2020). COVID-19's Mark on the ASEAN Economy. China Report ASEAN, 7,15-17

[43] Weigley, R. (1960). The American Way of War: A History of United States Military Strategy and Policy. Indiana University Press.

[44] Wu, Y.N. (2010). The Soft Power of India Viewed from Its Economic Reforms. Global Review, 4(1), 44-60.

[45] Yan, J.Y.(2010). Impact of Global Anti-Americanism on America's Soft Power. China International Studies, pp. 133-144.

[46] Yu, X.T. (2010). China's Public Relations and Soft Power. Global Review, 4(1), 22-33.

[47] Zhang, X.M. (2004). Attaching Importance to "Soft Power" Factor. Contemporary International Relations, 4, 38-43.

[48] Zhang, L. (2011). A Tentative Analysis of Soft Power and Its Usage in US Foreign Policies. Overseas English, pp. $380-383$.

[49] Zhao, L.Y. (2021). Economic Globalization in COVID-19 Pandemic and China's Leading Role. Contemporary World, 2021 (1), $28-31$.

[50] Zhao, W. (2021). Vaccine Diplomacy vs. Vaccine Hostility. Beijing Review, 2, 28. 